\title{
ОЗДОРОВИТЕЛЬНАЯ СОСТАВЛЯЮЩАЯ ЗАНЯТИЙ ЦИКЛИЧЕСКИМИ ВИДАМИ СПОРТА
}

\section{WELLNESS COMPONENT OF CLASSES CYCLICAL SPORTS \\ V. Bocharova \\ D. Yegorov \\ G. Zhovan}

Summary: The results of the survey of students on self-assessment of dependence on gadgets give high indicators. At the same time, tests of physical qualities demonstrate insufficient physical fitness. Systematic classes in cyclic sports help to develop endurance and introduce students to regular physical education classes. Running for $3000 \mathrm{~m}$. demonstrates the effectiveness of the work of the experimental groups.

Keywords: motor activity, health status, cyclic sports activities, aerobic loads, endurance, working capacity.
Бочарова Валерия Игоревна

К.п.н., дочент, Белгородский государственный национальный исследовательский университет bocharova_27@mail.ru

Егоров Дмитрий Евгеньевич

К.п.н., доцент, Московский политехнический университет

fiz_dimon@mail.ru

Жован Галина Федоровна

К.п.н., Белгородский государственный технологический университет им. В.Г. Шухова

jowan@mail.ru

Аннотация: Малая двигательная активность, использование электронных гаджетов приводит к снижению показателей здоровья. Результаты анкетирования студентов по самооценке зависимости от гаджетов дают высокие показатели. В то время, как тестирование физических качеств демонстрируют недостаточную физическую подготовленность. Системные занятия циклическими видами спорта помогают развить выносливость и приобщить к регулярным занятиям физической культурой студентов. Бег на 3000 м. демонстрирует результативность работы экспериментальных групп.

Ключевые слова: двигательная активность, состояние здоровья, циклические виды спортивной деятельности, аэробные нагрузки, выносливость, работоспособность.

ры и спорта, медицины, физиологии указывают на обеспечение необходимого уровня двигательной активности средствами ходьбы и беговых нагрузок $[2,4]$.

\section{Методы исследования}

Для исследования зависимости студентов от электронных устройств было проведено анкетирование по разработанной авторским коллективом анкете. Уровень развития физического качества выносливости определяли по результатам тестирования в беге на 3000 м. Использовался анализ результатов медицинского осмотра студентов и врачебного заключения с рекомендациями к занятиям физической культурой. В обработке результатов тестирования применялся метод математической статистики.

\section{Результаты исследований и их обсужАение}

Было проведено анкетирование студентов 1-3 курсов обучающихся в Белгородском государственном национальном исследовательском университете, Белгородском государственном технологическом университете им. В.Г. Шухова и Московском политехническом университете. Всего приняли участие более 3000 чело- 
век. Так на вопрос: «имеете ли вы в своем распоряжении смартфон» практически все 100\% опрошенных студентов ответили утвердительно, да имею. О функциях использования электронных гаджетов 100\% респондентов указали, что как телефон, так и как устройство с выходом в глобальную сеть интернета. На вопрос о временном количестве использования смартфона $85 \%$ опрошенных отметили промежуток от 4 до 6 часов в день. В большей степени это связано с перепиской, общением в мессенджерах, чтением новостей, поиском необходимой информации. Так же, используют гаджет по пути домой и на учебу, просматривая медиаконтент. Из числа анкетированных 10\% пользуются гаджетом от 2 до 4 часов в день. Остальные опрашиваемые, 5\% не задумывались над временем пользования гаджетом и предполагают, что пользуются ими значительно большее время, чем 6 часов в сутки. В ходе использования гаджета студенты чувствуют развивающееся утомление и неприятные ощущения в зрительном анализаторе. Такой физический дискомфорт студенты связывают с мелким шрифтом, необходимостью напряжения зрительного анализатора при рассмотрении материала.

На вопрос: «Испытываете ли вы тревогу если забыли смартфон», практически 100\% респондентов испытывают чувство тревоги, так как боятся пропустить «нужные» звонки. В том числе, основная масса студентов используют смартфон как средство для поиска необходимой информации в процессе учебной деятельности. Таким образом, можно считать верным существующие утверждения зависимости образа жизни студенческой молодежи от гаджетов. Это буквально подтвердили в анкетировании 92\% респондентов.

Низкий уровень физической подготовленности, в период начала учебного года продемонстрировали более 60\% всех студентов первых курсов. При выборе средств для оздоровления и повышения уровня выносливости мы взяли за основу постулат об эффективности занятий циклическими видами спорта и нагрузок аэробного характера в развитии выносливости.

В эксперименте приняли участие студенты первых курсов основного отделения. Были сформированы две группы, которые занимались по разработанной методике легкоатлетических занятий с использованием фитнес технологий.

Первая группа выполняла беговые нагрузки в условиях стадиона. При выполнении задания показатели пульса не превышал 150 уд/мин. Вторая группа, так же выполняла беговые нагрузки в условиях пересеченной местности, где пульс доходил до 180 уд/мин. Для определения интенсивности и длительности нагрузок, использовали индивидуальный подход с учетом исходного уровня физической подготовленности, результатов медицинского заключения. Основывались на данных, которые указывают, что высокоинтенсивные нагрузки вызывают более глубокие изменения и увеличивают время восстановления $[2,5]$.

Перед выполнением нагрузки обязательным условием было проведение разминки. Она включала в себя беговые упражнения, упражнения на повышение гибкости. После выполнения беговой нагрузки, студенты выполняли комплексы упражнений на укрепление мышц брюшного пресса, ног, рук и спины. Комплексы были разработаны одинаковые для всех групп.

Группы формировались с учетом пожеланий студентов к местам занятий и видам нагрузки. Перед экспериментом студентам был проведен теоретический курс о влиянии физических нагрузок на состояние здоровья, и уровень физической подготовленности. В процессе работы студенты подготовили рефераты о влиянии различных видов спортивной деятельности на развитие выносливости и состояние здоровья. Темы рефератов выбирались самостоятельно с учетом интересов, спортивного опыта. По результатам защиты работ был проведен очередной опрос, участников о влиянии подготовки реферата для осознанности физкультурных занятий. Все респонденты указали, что подготовка реферативной работы и взаимодействие с преподавателем способствовало расширению объема знаний и формированию собственной позиции в отношении занятий. Студенты отмечали, что в ходе выполнения теоретического задания были удовлетворены акцентом на постановку задач укрепления здоровья, улучшения физической подготовленности и поиска решений средствами физической культуры. Однако, информация чаще носила обобщенный опыт и общие рекомендации. В то время, как много больший интерес представляют индивидуальные программы тренировок с учетом не только физических возможностей и личных приоритетов, но и индивидуального режима дня, учебной занятости и даже времени года.

Результаты тестирования уровня выносливости оценивали в начале и конце эксперимента. За оценочный критерий были приняты нормативы комплекса ГТО для соответствующей возрастной группы в беге на дистанции 3000 метров. Результат, «золотого» значка, оценивался в 5 баллов. Показатели «серебряного» значка оценивали в 4 балла и 3 балла соответствовали результату «бронзового» значка. В начале эксперимента студенты, отобранные для занятий в экспериментальных группах № 1 и №2, продемонстрировали следующие результаты: соответствуя 5 баллам, дистанцию не преодолел никто, на 4 балла пробежали 12\% и 39\% показали результат на 3 балла. Остальные участники, их оказалось 49\%, показали неудовлетворительный результат и не сумели выполнить норматив. Результаты тестирования выносливости после работы по избранной методике продемонстриро- 
Таблица 1.

Сводная таблица результатов тестирования выносливости

\begin{tabular}{|c|c|c|c|c|}
\hline $\begin{array}{c}\text { Участники } \\
\text { и параметры оценки }\end{array}$ & $\begin{array}{l}\text { «Золотой» } \\
\text { значок ГТО }\end{array}$ & $\begin{array}{c}\text { «Серебряный» } \\
\text { значок } \\
\text { ГТО }\end{array}$ & $\begin{array}{c}\text { «Бронзовый» } \\
\text { значок } \\
\text { ГТО }\end{array}$ & Не выполнили норматив \\
\hline & 5 баллов & 4балла & 3 балла & 0 баллов \\
\hline Экспериментальная группа №1 & $11 \%$ & $23 \%$ & $40 \%$ & $26 \%$ \\
\hline Экспериментальная группа №2 & $18 \%$ & $23 \%$ & $51 \%$ & $8 \%$ \\
\hline Контрольная группа & $1 \%$ & $18 \%$ & $54 \%$ & $27 \%$ \\
\hline
\end{tabular}

ваны в таблице 1. Значительный прирост наблюдался в показателях выносливости в экспериментальных группах в сравнении с контрольной. В контрольной группе, занимающейся элективными дисциплинами по физической культуре и спорту, демонстрировали не столь значительные изменения.

С результатом, соответствующим 5 баллам в начале эксперимента дистанцию, никто не преодолел. Результативность, соответствующую 4 баллам, выполнили 10\%. Результаты, соответствующие 3 баллам, показали 42\% студентов. 48\% участников этой, контрольной группы с тестом первоначально не справились.

В завершающей части эксперимента был проведен еще один опрос студентов имевший цель обобщить мнения участников о программе и влиянии нагрузок циклического характера на психологическое состояние. Так студенты указали, что данные занятия способствовали снятию психологического напряжения от учебной нагрузки, переживаний при подготовке к зачетной, или экзаменационной сессии. Так же полученные теоретические знания и практический опыт помогают студентам построить систему самостоятельных занятий. Студенты двух экспериментальных групп осознанно используют занятия циклическими видами спортивной деятельности не только с целью коррекции веса или физических кондиций, но и с целью оздоровления. Тогда как в контрольной группе, студенты указали, что знают о положительном воздействии занятий различными видами спорта. Механизма оздоровительного воздействия, опрошенные студенты контрольной группы, не знают. Систему самостоятельных занятий построить не могут. Такие студенты отмечают, что есть фитнесс клубы, там они и будут заниматься при необходимости.

\section{Выво $\Delta ы$}

В результате исследования мы пришли к подтверждению мнения о значительном времени прибывания современной молодежи с гаджетами. Их малой двигательной активности, незначительных знаниях о возможностях улучшения состояния здоровья. Показатели физического качества выносливости у студентов оцениваются как низкие.

Простые и доступные для самостоятельных занятий программы с постановкой цели и этапных задач способны в достаточно короткие сроки демонстрировать значительные результаты, в режиме работы при пульсе 180 уд/мин и более только индивидуально, и только при разрешающих рекомендациях врача. Циклические виды спортивной деятельности, в частности беговые нагрузки, наиболее эффективны в развитии выносливости и оказывают оздоровительное воздействие в режиме показателей ЧСС от 150 до 170 уд/мин. Такие занятия физической культурой закрепляют положительные эмоции и способствуют дальнейшим самостоятельным занятиям циклическими видами спорта. Одновременное формирование теоретических знаний в области физической культуры, оздоровительных систем побуждает к самообразованию студента и поискам индивидуально привлекательных видов двигательной активности.

\section{ЛИТЕРАТУРА}

1. Беликова И.В., Радченко Н.Р., Кустарева Л.П. Мониторинг состояния здоровья населения в контексте развития общественного здравоохранения // Здоровье человека, теория и методика физической культуры и спорта. - 2019. - № 4 (15). - С. 257-261.

2. Егоров Д.Е. Технология поэтапного повышения уровня физической подготовленности студенток вузов гуманитарного профиля: Дис.... канд. пед. наук: 13.00.04 - Хабаровск, 2000. - 167 с.

3. Крамской С.И., Замчевская Е.С., Жован Г.Ф. Физическая культура и спорт. Организация работы специального учебного отделения: учебное пособие / С.И. Крамской, Е.С. Замчевская, Г.Ф. Жован. - Белгород: БГтУ, 2021. - 105 с.

4. Лотоненко А.В. Эффективность средств и методов повышения физической работоспособности студентов: Дис... канд. пед. наук: 13.00 .04 - Ленинград, 1981. -198 C. 
5. Сигида И.Р., Казанцева Е.В. Номофобия как вариация зависимого поведения в студенческой среде //Актуальные проблемы профилактики аддиктивного поведения: Материалы I Региональной научно-практической конференции, 25 октября 2017 г. - Таганрог: ТИ им. А.П. Чехова, 2018. - С. 96-98

6. Сидорина Л.В., Минка И.Н. Приоритет здоровья студентов АМГПГУ уровень валеологической грамотности студентов АМГПГУ// Амурский гуманитарнопедагогический государственный университет. - 2017 - № 1. - С. 75-79.

7. Чижкова М.Б. Взаимосвязь здоровья студентов-первокурсников с адаптацией к образовательной среде медицинского вуза // Психолог. - 2020. № 6. - C. $38-55$.

8. Шевырдяева К.С., Лыгина М.А. Изучение ориентации студентов на ведение здорового образа жизни и сформированности ценностного отношения студентов к здоровью // Известия высших учебных заведений. Поволжский регион. Гуманитарные науки. - 2017. - № 4 (44). - С. 162-167.

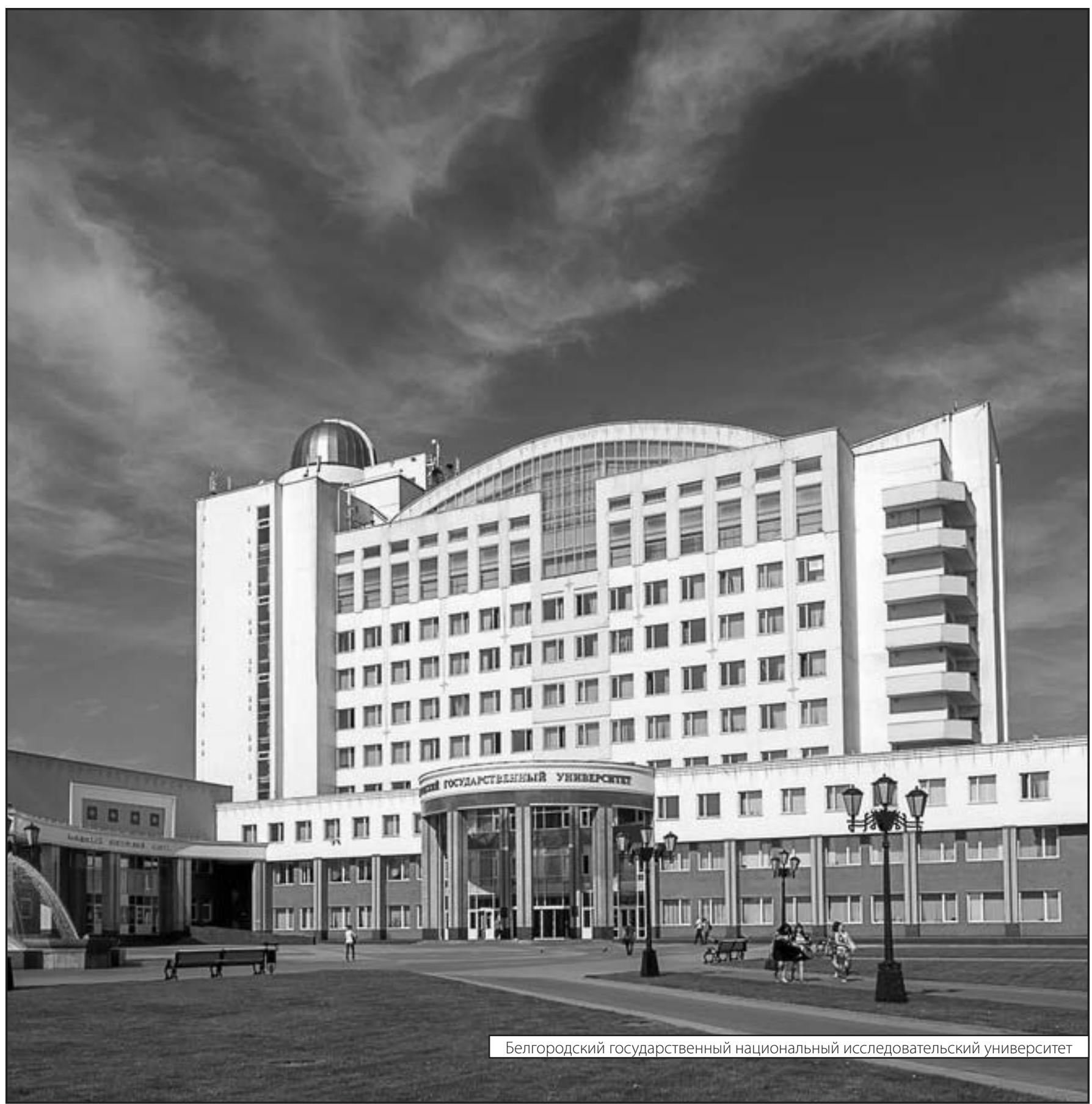

